\title{
PELAKSANAAN TUGAS KELUARGA DI BIDANG KESEHATAN: MENGAMBIL KEPUTUSAN MENGENAI TINDAKAN KESEHATAN YANG TEPAT TERHADAP KEJADIAN HIPERTENSI PADA LANSIA DI KELURAHAN TIMBANGAN KECAMATAN INDRALAYA UTARA KABUPATEN OGAN ILIR
}

\author{
Madepan Mulia \\ Akademi Keperawatan Panca Bhakti Bandar \\ Lampung Email: madefikui@gmail.com
}

\begin{abstract}
ABSTRAK
Hipertensi adalah salah satu penyebab kematian nomor satu secara global yang memerlukan penanggulangan yang baik. Hasil Survei Kesehatan Rumah Tangga (SKRT) tahun 2007 menunjukkan bahwa prevalensi penyakit hipertensi pada lansia di Indonesia cukup tinggi, yaitu 83 per 1.000 anggota rumah tangga. Data dari Dinas Kesehatan Kabupaten Ogan Ilir tahun 2010 menunjukkan bahwa hipertensi merupakan penyakit terbanyak ketiga yang menyerang lansia. Penelitian ini bertujuan untuk mengetahui hubungan pelaksanaan tugas keluarga di bidang kesehatan: mengambil keputusan mengenai tindakan kesehatan yang tepat terhadap kejadian hipertensi pada lansia. Penelitian ini merupakan penelitian analitik kuantitatif dengan pendekatan cross sectional. Penelitian ini dilakukan terhadap keluarga dengan anggota keluarga lansia yang berusia lebih dari 60 tahun yang tersebar di Kelurahan Timbangan yang berjumlah 94 responden, dengan menggunakan alat bantu kuesioner. Untuk menguji hubungan digunakan analisis menggunakan uji Chi-Square. Hasil penelitian menunjukkan bahwa ada hubungan antara pelaksanaan tugas keluarga di bidang kesehatan: mengambil keputusan mengenai tindakan kesehatan yang tepat terhadap kejadian hipertensi $(\mathrm{p}=0,000)$. Dari hasil penelitian ini disarankan kepada keluarga agar dapat meningkatkan derajat kesehatan dan mengatasi masalah kesehatan anggota keluarganya, khususnya lansia, dengan mengambil keputusan mengenai tindakan kesehatan yang tepat terkait penyakit hipertensi pada lansia.
\end{abstract}

Kata kunci: Hipertensi, lansia, tugas keluarga di bidang kesehatan

\begin{abstract}
Hypertension is one of the number one causes of death globally that needs a good response. Results of Household Health Survey (SKRT) in 2007 showed that prevalence of hypertension disease in elderly in Indonesia is quite high, that is 83 per 1,000 household members. Data from the District Health Office Ogan Ilir in 2010 showed that hypertension is the third disease that attacks the elderly. This study aims to determine the relationship of family duties in the field of health: make decisions about appropriate health measures with the incidence of hypertension in the elderly. This research is a quantitative analytical research with cross sectional approach. This study was conducted on families with elderly family members aged over 60 years scattered in the village of Timbangan, which amounted to 94 respondents, using a questionnaire tool. To test the relationship used analysis using Chi-Square test. The results showed that there was a relationship between the implementation of family duty in the field of health: make decisions about appropriate health measures with the incidence of hypertension $(p=0.000)$. From the results of this study suggested to the family in order to improve the degree of health and to overcome the health problems of family members, especially the elderly, by performing family duties in the field of health is make decisions about appropriate health measures for the elderly.
\end{abstract}

Keywords: Hypertension, elderly, family duty in the field of health 


\section{PENDAHULUAN}

Keluarga adalah kumpulan dua orang atau lebih yang hidup bersama dengan keterikatan aturan dan emosional dimana individu mempunyai peran masing-masing yang merupakan bagian dari keluarga. Keluarga merupakan unit pelayanan dasar di masyarakat yang juga merupakan perawat utama dalam anggota keluarga. Keluarga dipandang sebagai suatu sistem, dimana keluarga mempengaruhi seluruh keluarga dan sebaliknya keluarga mempengaruhi status kesehatan anggota keluarga yang lain (Friedman, 1998).

Dalam upaya peningkatan derajat kesehatan dan mengatasi masalah kesehatan anggota keluarganya, keluarga harus mampu melaksanakan fungsi perawatan kesehatan

keluarga. Berdasarkan hasil penelitian menunjukkan bahwa ada hubungan pelaksanaan fungsi perawatan kesehatan keluarga pada keluarga yang mempunyai anak usia 0-4 tahun dengan frekuensi kejadian ISPA dengan nilai $\mathrm{p}$ value $0,030(\alpha<0,05)$ (Khodariyah, 2009). Fungsi perawatan kesehatan keluarga dapat berfungsi dengan baik jika keluarga dapat melaksanakan tugas keluarga di bidang kesehatan dengan baik pula.

Kesanggupan keluarga melaksanakan fungsi perawatan kesehatan keluarga dapat dilihat dari lima tugas keluarga di bidang kesehatan yang dilaksanakan. Pelaksanaan lima tugas keluarga dibidang kesehatan tersebut meliputi mengenal masalah kesehatan keluarga, mengambil keputusan mengenai tindakan kesehatan yang tepat bagi keluarga, merawat keluarga yang mengalami gangguan kesehatan, memodifikasi lingkungan keluarga untuk menjamin kesehatan keluarga dan memanfaatkan fasilitas pelayanan kesehatan di sekitarnya bagi keluarga (Setyowati, Sri \& Murwani, 2008).

Pelaksanaan tugas keluarga di bidang kesehatan sangat diperlukan dalam upaya pencegahan dan mengatasi masalah kesehatan keluarga, khususnya lansia sebagai bagian dari anggota keluarga yang memerlukan perawatan yang lebih ditujukan untuk memenuhi kebutuhan akibat proses penuaan. Salah satunya adalah penanganan terhadap penyakit degeneratif yang banyak diderita oleh lansia yang sering menimbulkan kecacatan (Mubarak et.al., 2001).

Persentase lima penyakit degeneratif utama yang banyak diderita oleh lansia di Indonesia adalah anemia sebesar 50\%, penyakit kardiovaskuler sebesar 29,5\%, infeksi saluran pernafasan sebesar $12,2 \%$, penyakit kanker sebesar 12,2\% dan penyakit TBC 11,5\% (Riset Kesehatan Dasar, 2013). Salah satu penyakit degeneratif pada lansia yang menyerang sistem kardiovaskular adalah hipertensi atau peningkatan tekanan darah. Hipertensi adalah kondisi medis ketika seseorang mengalami peningkatan tekanan darah di atas normal dalam jangka waktu yang lama (Sudarmoko, 2010). Seorang lansia dikatakan menderita hipertensi bila tekanan darahnya mencapai 160/90 mmHg (Smeltzer \& Bare, 2002). 
Peningkatan tekanan darah hingga mencapai 160/90 mmHg pada lansia dipengaruhi oleh beberapa faktor. Faktor- faktor yang meningkatkan risiko hipertensi adalah obesitas dan kebiasaan merokok (Mansjoer, et.al., 2001). Hasil analisis faktor risiko yang berkaitan dengan kejadian hipertensi pada lansia di wilayah kerja Puskesmas Kroya Kabupaten Cilacap tahun 2005, diperoleh hasil bahwa faktor risiko kejadian hipertensi pada lansia meliputi kebiasaan merokok, kebiasaan minum kopi, konsumsi daging berlemak, faktor genetik dan stress psikologis. Kebiasaan hidup yang baik seperti mengurangi kebiasaan merokok, pola makan yang berlebihan, konsumsi lemak berlebih serta kebiasaan hidup yang tidak sehat merupakan cara yang paling tepat dalam upaya mengurangi peningkatan kejadian hipertensi (Sulistiani, 2005).

Prevalensi penyakit hipertensi pada lansia di Indonesia cukup tinggi, yaitu 83 per

1.000 anggota rumah tangga (Riset Kesehatan Dasar, 2013). Di Provinsi Sumatera Selatan, prevalensi hipertensi pada tahun 2008 sebesar 9,17\% dan di Kabupaten Ogan Ilir, prevalensi hipertensi pada tahun 2010 sebesar 15,9\%. Data dari Dinkes Ogan Ilir tahun 2010 menunjukkan bahwa hipertensi merupakan penyakit terbanyak ketiga yang menyerang lansia setelah penyakit degeneratif lainnya (rematik dan ISPA).

Berdasarkan hasil studi pendahuluan yang dilakukan di Puskesmas Timbangan, didapatkan data bahwa penyakit tidak menular terbanyak pada lansia adalah penyakit hipertensi. Angka kunjungan penderita hipertensi ke Puskesmas Timbangan adalah sebesar 38,6\% yang menempati posisi lebih tinggi daripada angka kejadian hipertensi di Kabupaten Ogan Ilir yang hanya sebesar $15,9 \%$. Selain itu, kunjungan penderita hipertensi ke Puskesmas Timbangan lebih banyak berasal dari kelompok lansia yaitu berumur lebih dari 60 tahun sehingga peneliti mengambil penderita hipertensi dari kelompok lansia.

Berdasarkan studi pendahuluan yang dilakukan di Kantor Kelurahan Timbangan, didapatkan data bahwa jumlah lansia di Kelurahan Timbangan adalah sebesar $48 \%$ dari seluruh jumlah lansia yang berada di wilayah kerja Puskesmas Timbangan. Hal ini menunjukkan bahwa hampir sebagian dari seluruh lansia yang berada di wilayah kerja Puskesmas Timbangan berada di Kelurahan Timbangan, sehingga peneliti memilih Desa Kelurahan Timbangan sebagai tempat penelitian.

Berdasarkan hasil wawancara kepada keluarga di Kelurahan Timbangan, didapatkan bahwa 4 dari 5 keluarga mengatakan masih sering mengkonsumsi makanan yang mengandung tinggi lemak dan kolesterol, seperti makanan yang bersantan dan gorengan. Keluarga pun masih sering mengkonsumsi makanan yang asin-asin dan seringkali menambahkan banyak garam dan gula ke dalam makanannya yang dapat berpotensi meningkatkan tekanan darah dan risiko obesitas. Selain itu, kebiasaan 
mengkonsumsi makanan siap saji yang tinggi akan natrium dan Monosodium Glutamate (MSG) atau sering disebut penyedap rasa pun masih sering dilakukan.

Dipihak lain, perawat sebagai peneliti bertanggung jawab untuk memberikan bantuan keperawatan dalam upaya penyembuhan dan pencegahan terjadinya hipertensi pada lansia. Peran perawat sebagai peneliti adalah mengembangkan keperawatan keluarga dan memberikan gambaran baru kepada keluarga tentang pemenuhan kebutuhan perawatan serta pengenalan kebutuhan lansia dengan hipertensi sehingga diperoleh satu kesatuan antara tercapainya peran keluarga dalam pelaksanaan tugas keluarga dibidang kesehatan dan terpenuhinya kebutuhan perawatan yang diperlukan lansia yang dirawat di dalam kehidupan keluarga.

\section{METODOLOGI}

Penelitian ini merupakan penelitian analitik kuantitatif dengan desain cross sectional. Populasi yang digunakan dalam penelitian ini adalah sebanyak 123 keluarga (yang melaksanakan tugas keluarga dibidang kesehatan yaitu istri atau anak perempuan), dengan anggota keluarga lansia yang berusia lebih dari 60 tahun. Metode yang digunakan adalah purposive sampling. Sampel sebanyak 94 keluarga dengan anggota keluarga lansia yang yang berusia lebih dari 60 tahun. Penelitian dilakukan pada tanggal 27 Mei 2011 - 12 Juni 2011.

\section{HASIL}

Hubungan antara kemampuan keluarga mengambil keputusan mengenai tindakan kesehatan yang tepat bagi lansia dengan kejadian hipertensi pada lansia Di Kelurahan Timbangan Kecamatan Indralaya Utara Kabupaten Ogan Ilir dapat dilihat pada tabel 1.

Tabel 1

Hubungan Kemampuan Keluarga Mengambil Keputusan Mengenai Tindakan Kesehatan Yang Tepat Bagi Lansia Dengan Kejadian Hipertensi Pada Lansia

\begin{tabular}{ccc}
\hline $\begin{array}{c}\text { Mengenal } \\
\text { masalah } \\
\text { hipertensi pada } \\
\text { lansia }\end{array}$ & P Value & OR (95\% CI) \\
\hline \begin{tabular}{c} 
Baik \\
\hline Tidak baik
\end{tabular} & 0,000 & 8,932 \\
\hline Total & & $(3,304-21,313)$ \\
\hline
\end{tabular}

Dari hasil tabel silang antara kemampuan keluarga mengambil keputusan mengenai tindakan kesehatan yang tepat bagi lansia dengan kejadian hipertensi pada lansia di Kelurahan Timbangan Kecamatan Indralaya Utara Kabupaten Ogan Ilir yang diperlihatkan pada tabel 1, didapatkan hasil bahwa keluarga yang mengambil keputusan mengenai tindakan kesehatan yang tepat bagi lansia dengan baik maka kejadian hipertensi pada lansia akan cenderung lebih sedikit yaitu sebanyak 11 lansia $(26,8 \%)$ dan keluarga yang tidak baik dalam mengambil keputusan mengenai tindakan kesehatan yang tepat bagi lansia maka kejadian hipertensi pada lansia akan cenderung lebih banyak yaitu sebanyak 40 lansia $(75,5 \%)$.

Hasil uji statistik dengan Chi-square menunjukkan nilai $\mathrm{p}$ value $=0,000(\alpha<0,05)$, maka dapat disimpulkan bahwa terdapat 
hubungan bermakna (signifikan) antara kemampuan keluarga mengambil keputusan mengenai tindakan kesehatan yang tepat bagi lansia dengan kejadian hipertensi pada lansia di Kelurahan Timbangan Kecamatan Indralaya Utara Kabupaten Ogan Ilir. Dari hasil analisis diperoleh pula nilai $\mathrm{OR}=8,392$, artinya keluarga yang tidak baik dalam mengambil keputusan mengenai tindakan kesehatan yang tepat bagi lansia berpeluang 8,392 kali untuk terjadinya hipertensi pada lansia.

\section{PEMBAHASAN}

Dari hasil penelitian didapatkan bahwa keluarga yang mengambil keputusan mengenai tindakan kesehatan yang tepat bagi lansia dengan baik maka kejadian hipertensi pada lansia akan cenderung lebih sedikit yaitu 26,8\% dan keluarga yang tidak baik dalam mengambil keputusan mengenai tindakan kesehatan yang tepat bagi lansia maka kejadian hipertensi pada lansia akan cenderung lebih banyak yaitu 75,5\%. Hasil uji statistik dengan Chi-square menunjukkan nilai $\mathrm{p}$ value $=0,000(\alpha<0,05)$, maka dapat disimpulkan bahwa terdapat hubungan bermakna antara kemampuan keluarga mengambil keputusan mengenai tindakan kesehatan yang tepat bagi lansia dengan kejadian hipertensi pada lansia di Kelurahan Timbangan Kecamatan Indralaya Utara Kabupaten Ogan Ilir tahun 2011.

Hasil penelitian ini sesuai dengan hasil penelitian yang dilakukan oleh Wahyuni (2007) dalam penelitiannya mengenai hubungan perilaku pengaturan diet keluarga dengan kejadian hipertensi pada kelompok usia dewasa menengah di Kelurahan Plaju Palembang dengan nilai $\mathrm{p}$ value $=0,000(\alpha<$ $0,05)$, yang menyatakan bahwa terdapat hubungan bermakna antara sikap keluarga dalam pengaturan diet dengan kejadian hipertensi pada kelompok usia dewasa menengah.

Keluarga yang mampu memutuskan tindakan apa yang seharusnya dilakukan dalam upaya mencegah dan memberikan perawatan yang tepat bagi lansia yang menderita hipertensi, akan mempermudah keluarga untuk memberikan perawatan. Dengan sikap keluarga yang memberikan dukungan terhadap upaya pencegahan dan perawatan, maka akan lebih mudah menciptakan suatu kondisi yang sehat terhadap anggota keluarga, khususnya lansia yang menderita hipertensi. Sesuai dengan pernyataan Notoatmodjo (2010) bahwa untuk menciptakan suatu kondisi yang sehat dan terkontrol, maka keluarga diharapkan mempunyai pengetahuan dan sikap tentang penyakit hipertensi agar tercipta suatu perilaku perawatan yang tepat pada penderita hipertensi, dalam hal pencegahan, penatalaksanaan yang benar dan tepat pada penderita hipertensi.

Hasil analisis univariat memperlihatkan sebanyak 53 keluarga $(56,4 \%)$ tidak baik dalam mengambil keputusan mengenai tindakan kesehatan yang tepat bagi lansia. Dapat disimpulkan bahwa keluarga belum memiliki suatu sikap yang baik dalam memutuskan tindakan apa yang seharusnya 
dilakukan dalam upaya mencegah dan memberikan perawatan yang tepat bagi lansia yang menderita hipertensi, sehingga hal inilah yang mempersulit keluarga untuk memberikan perawatan. Menurut analisis peneliti, kurang baiknya keluarga dalam mengambil keputusan mengenai tindakan kesehatan yang tepat bagi lansia disebabkan oleh kurangnya informasi yang didapatkan keluarga terkait informasi mengenai kesehatan.

Kurangnya informasi menyebabkan kurangnya pengetahuan dan pada akhirnya menyebabkan sikap dalam mengambil keputusan mengenai tindakan kesehatan yang tepat bagi lansia pun menjadi kurang baik. Sesuai Allport dikutip Notoatmodjo (2010) yang menyatakan bahwa penentuan sikap keluarga dalam mengambil keputusan mengenai tindakan kesehatan yang tepat bagi lansia dipengaruhi oleh pengetahuan. Selain itu, hal ini juga sesuai dengan pernyataan Wahyuni (2007) bahwa apabila pengetahuan tentang hipertensi cukup baik akan berpengaruh pada sikap yang baik pula pada keluarga untuk melakukan perawatan yang tepat pada anggota keluarga yang menderita hipertensi.

Keluarga akan memutuskan mengenai tindakan kesehatan yang tepat bagi lansia jika mereka tahu mengenai apa yang seharusnya baik untuk dilakukan dan tidak baik untuk dilakukan begitu pula sebaliknya. Sesuai dengan Notoatmodjo (2010) yang menyatakan bahwa sikap adalah respon seseorang terhadap objek tertentu yang melibatkan faktor pendapat dan emosi yang bersangkutan (senang- tidak senang, setuju-tidak setuju atau baik- tidak baik). Perawat pada fase ini berperan penting dalam membimbing keluarga untuk mengenali irrasionalitas pada keyakinan-keyakinan tertentu mengenai konsekuensi atas tindakan yang telah dilakukan. Perawat harus bisa memastikan bahwa keluarga telah mempunyai pengetahuan yang benar dan penanganan yang tepat terhadap penyakit hipertensi.

Perawat dapat memberikan penjelasan mengenai akibat lanjut yang ditimbulkan apabila penanganan terhadap penderita hipertensi tidak tepat, yaitu penyakit stroke yang dapat mengakibatkan lansia tidak dapat melakukan aktivitas secara mandiri, bahkan dapat terjadi kematian. Selain itu, hipertensi yang tidak terkontrol juga akan menyebabkan kerusakan organ tubuh seperti otak, ginjal, mata dan jantung serta kelumpuhan anggota gerak.

\section{KESIMPULAN}

Ada hubungan bermakna ( $\mathrm{p}$ value $=0,000$ berarti $\mathrm{p}$ value $<0,05)$ antara kemampuan keluarga mengambil keputusan mengenai tindakan kesehatan yang tepat bagi lansia dengan kejadian hipertensi pada lansia di Kelurahan Timbangan Kecamatan Indralaya Utara Kabupaten Ogan Ilir.

\section{SARAN}

Hasil penelitian ini diharapkan dapat memberikan informasi atau gambaran kepada masyarakat, khususnya keluarga mengenai pentingnya pelaksanaan tugas keluarga di bidang kesehatan: mengenal masalah 
hipertensi dalam upaya penyembuhan dan pencegahan terjadinya hipertensi pada lansia.

\section{KEPUSTAKAAN}

Dinas Kesehatan Kabupaten Ogan Ilir. (2010). Profil Kesehatan Kabupaten Ogan Ilir Tahun 2008. Ogan Ilir: Dinas Kesehatan Kabupaten Ogan Ilir.

Friedman, Marylin M. (1998). Keperawatan Keluarga: Teori dan Praktek_edisi 3. Jakarta: EGC.

Khodariyah, Laelatul. (2009). Hubungan Pelaksanaan Fungsi Perawatan Kesehatan Keluarga Pada Keluarga Yang Mempunyai Anak Usia 0-4 Tahun Dengan Frekuensi Kejadian Ispa Di Desa Tanggung Kecamatan Tanggungharjo Kabupaten Grobogan. http://digilib.unimus.ac.id/, diperoleh tanggal 16 Maret 2013.

Mansjoer, Arif et al. (2001). Kapita Selekta Kedokteran_edisi 3. Jakarta: Media Aesculapius.

Mubarak, Wahit Iqbal et al. (2010). Ilmu Keperawatan Komunitas: Konsep dan Aplikasi. Jakarta: Salemba Medika.

Notoatmodjo, Soekidjo. (2010). Ilmu Perilaku Kesehatan. Jakarta: PT Rineka Cipta.

Riset Kesehatan Dasar. (2013). Jakarta: Badan Penelitian dan Pengembangan Kesehatan, Departemen Kesehatan Republik Indonesia

Setyowati, Sri \& Murwani, A. (2008). Asuhan Keperawatan Keluarga: Konsep dan Aplikasi Kasus. Yogyakarta: Mitra Cendikia.

Smeltzer, S. C., \& Bare, B. G. (2002). Keperawatan Medikal-

Bedah_Volume 3. Jakarta: EGC.

Sudarmoko, Arief. (2010). Tetap Tersenyum Melawan Hipertensi. Yogyakarta: Atma Media Press.

Sulistiani, Widi (2005). Analisis Faktor Risiko Yang Berkaitan

Dengan Kejadian Hipertensi Pada Lansia Di Wilayah Kerja Puskesmas Kroya I Kabupaten Cilacap. http://eprints.undip.ac.id/5212/1/243

8.pdf, diperoleh tanggal 16 Maret 2011.

Wahyuni, Nyimas S., (2007). Hubungan Perilaku Pengaturan Diet Keluarga
Dengan Kejadian Hipertensi Pada Kelompok Usia Dewasa Menengah Di Kelurahan Plaju Palembang. Palembang : PSIK FK UNSRI. 